\title{
Psychometric Characteristics of an Intimate Partner Violence Screening Tool in Women With Mental Disorders
}

\author{
Behnaz Salahi ${ }^{1}$, Sakineh Mohammad-Alizadeh-Charandabi2 ${ }^{*}$, Fatemeh Ranjbar ${ }^{3}$, Niloofar \\ Sattarzadeh-Jahdi ${ }^{2}$, Solmaz Abdollahi ${ }^{4}$, Fariba Nikan ${ }^{5}$, Rogayeh Alizadeh-Asl ${ }^{6}$
}

\begin{abstract}
Objectives: Quick recognition of intimate partner violence (IPV) victimization is important in women with mental disorders. Therefore, we assessed the accuracy of the brief and comprehensive 8-item woman abuse screening tool (WAST) and its 2-item short form (WAST-SF) by comparison to the reference standard for past year IPV with the 39-item revised conflict tactics scale (CTS-2) at this population.

Materials and Methods: In this cross-sectional study, 400 women with mental disorders within the age range of 19-49 years were interviewed using the WAST and CTS-2 at a psychiatric hospital in Tabriz, Iran. Receiver operating characteristic (ROC) was used to determine characteristics of the screening tools.

Results: All types of IPV were very common in the past year; $90 \%$ overall, $86 \%$ psychological aggression, $62 \%$ physical assault, $53 \%$ sexual coercion and 53\% injury. The highest diagnostic accuracy of WAST was at the cutoff score of 12 (area under the curve [AUC] $0.90,95 \%$ CI 0.83 to 0.96 ) with $96 \%$ ( $93 \%$ to $98 \%$ ) sensitivity and $84 \%$ (67\% to $93 \%)$ specificity. Predictive values of the optimal score were $99 \%$ (97\% to $99.4 \%$ ) for victims and $64 \%$ (48\% to77\%) for non-victims. Its agreement with CTS2 was good ( $\mathrm{r}=0.69)$. The highest diagnostic accuracy of WAST-SF was at the cutoff score of 3 (AUC $84 \%, 95 \%$ CI 0.77 to 0.91 ) with sensitivity $93 \%$, specificity $71 \%$, positive predictive value $97.5 \%$, and negative predictive value $47 \%$.

Conclusions: The WAST at cutoff score of 12 and WAST-SF at cutoff score of 3 have good accuracy in diagnosis of the past year IPV among women with mental disorders. Healthcare providers at psychiatric facilities should use these tools for IPV screening.

Keywords: Intimate partner violence, Mental disorders, Screening
\end{abstract}

\section{Introduction}

Violence refers to any act that results in physical, sexual, or psychological harm or individual's suffering and it includes threats, coercion, and deprivation of freedom whether occurring in public or in private life. About $1 / 3$ of women experience physical or sexual violence by an intimate partner (1). Domestic violence exists in all societies with varied prevalence rates. In a national survey conducted in 28 provinces of Iran, the reported prevalence of violence against women was $66 \%$ (2). However, we found no study on the prevalence of violence in women with psychiatric diseases in Iran.

Adverse effects of domestic violence on health are the same around the world but may vary from short-term to long-term physical and mental effects, including anxiety, depression, post-traumatic stress, substance abuse to suicide, and violence-induced death $(3,4)$

There is an association between intimate partner violence (IPV) against women and mental disorders. A systematic review indicates a greater likelihood of IPV victimization in women across all mental disorders (5). In addition, women with mental illnesses are more vulnerable to violence. It increases duration and recurrence of the disease $(6,7)$, as well as the likelihood of suicide attempts, substance abuse, noncompliance with treatment, and disruption of family and social relations $(8,9)$. On the other hand, another systematic review showed that IPV victimization significantly increases the occurrence of most mental disorders like perinatal depression and anxiety (10). For example, a study in Turkey indicated significant relationships between violence against infertile women and mental health sequels including depression, anxiety, psychosomatic symptoms, homicide, and suicide (11).

Although the routine assessment of domestic violence by psychiatric services has been emphasized in international 
guidelines, the services often fail to identify the experience of violence in their clients (12). The providers report the lack of time and a short, robust and reliable tool as common barriers of violence screening (13).

A perfect tool for violence screening is a tool that encompasses different aspects of violence, including physical, psychological, and sexual aspects, with its psychometrics assessed in the same population (14). Understanding the scope of violence helps healthcare providers plan properly and specifically to help the victims. It seems that woman abuse screening tool (WAST), among many tools for violence screening, can be a perfect tool for women with psychiatric diseases, as it assesses a variety of physical, psychological, and sexual abuse with a small number of items ( 8 items) and easy implementation. Also, the use of its short form, with just 2 items, is recommended in busy centers $(13,15)$. Furthermore, it has high reliability and good sensitivity and specificity (10).

A recent systematic review (12) recommended more studies to examine the psychometric properties of WAST in people with mental disorders. Also, the psychometric properties of WAST have not been measured in no community in Iran. Therefore, we assessed the accuracy and psychometric characteristics of WAST and its 2-item short form (WAST-SF) for identifying IPV compared to the revised conflict tactics scale (CTS-2), widely used as a reference instrument $(15,16)$ in Iranian women with mental disorders.

\section{Materials and Methods}

This cross-sectional study recruited 19-49-year-old married eligible women with psychiatric disorders, who were hospitalized in Razi Teaching Hospital, Tabriz, Iran or presented outpatient clinic of the hospital during the study and had willing to participate. This hospital is the only center providing inpatient psychiatry services in the northwest of Iran. The structured clinical interview for DSM-IV axis I disorders (SCID-I) and axis II disorders (SCID-II) (a standard method for the diagnosis of patients with clinical symptoms) were used by a psychiatrist to diagnose participant' disease. All participants were using medicines to control their diseases. Women with less than 12 months of marriage, those who were divorced over 12 months, and those with diagnosis of mental retardation, cognitive disorders, or dementia were excluded.

Data were collected through face-to-face interviews with patients when they were in a stable situation, with inpatients just before their discharge and with outpatients after they were visited by the physician if they were stable. Before the interview, the research objectives, method, and confidentiality of information were explained to the participants and written informed consent was taken from them. The data were collected using WAST, CTS-2, and a demographic questionnaire, respectively.

WAST was originally developed by Brown et al for family physicians to screen current physical, psychological and, sexual abuse in women and more than $90 \%$ of women have reported being comfortable or very comfortable with it. Validity and reliability of the original version have been confirmed in different studies. High internal consistency (Cronbach a: 0.75$)$, sensitivity (92\%), specificity (100\%), and a high correlation with Abuse Rating Inventory $(r=0.96)$ have been reported for this tool $(17,18)$. It has 3 response categories ( 1 to 3 ) for each item related to violence or as a predictor of violence.

The first 2 items, known as WAST-short form (WAST$\mathrm{SF}$ ), was used for screening of abuse presence. It assesses the level of tension a woman feel in relationship with her husband/partner and the amount of difficulty that they have in resolving the arguments scaled from 1 (no tension/no difficulty) to 3 (a lot of tension/great difficulty). The next 6 items were used to gain a complete assessment of the frequency of various feelings and 3 areas of IPV (physical, sexual, and psychological) on a scale of 1 (never) to 3 (often). Total score for overall WAST ranges from 8 to 24 and for WAST-SF ranges from 2 to 6 . The tool developers have proposed cut-off point 13 as violence for the overall 8-item WAST score (18). In dichotomous scoring of WAST-SF, the score of 0 is considered as 'no tension/no difficulty' and the score of 1 as the other response categories and the total score of 1 and more is considered as presence of abuse (19).

We used translation, face, and content validity of Persian version of the WAST. At first, its translation validity was confirmed by forward and backward strategy. Then the questionnaire was given to 10 faculty members of midwifery, psychiatry, psychology and necessary corrections were made after collecting their comments. Moreover, a pilot study was conducted on 20 convenient subjects to evaluate face validity and possible problems. Reliability of the tool was evaluated by test-retest (ICC = intraclass correlation) with the interval of 1 week and by internal consistency using Cronbach a coefficient. Cronbach $\alpha$ and ICC were $83 \%$ and 0.79 (95\% CI: 0.55$0.91)$, respectively.

CTS2 are the most widely used instrument for screening domestic violence which assesses prevalence with 5 subscales including negotiation, psychological aggression, physical assault, sexual coercion, and injury. Overall, it has 39 pairs of items with 8 response categories ( 0 to 7 ) for each item; the category 0 corresponds with "never" and category 7 corresponds with "not in the past 12 months but it did happen before", the 1 to 6 response categories correspond with "once"; "twice"; " 3 to 5 times"; "6 to 10 times"; "11 to 20 times"; and "more than 20 times" in the past 12 months, respectively (20).

A response of 1 to 6 for any item of each scale was considered as presence, and responses of 0 or 7 for all items of the scale was considered as absence of that type of IPV. Report of experiencing violence at least once in any types of the psychological aggression, physical assault, sexual coercion, or injury was considered as presence of overall IPV.

We transformed the response for each item as 1 (for 1 
to 6) and 0 (for 0 or 7). We considered having experienced at least one violent act within the past year as presence of violence.

CTS2 has high internal consistency. It is reported Cronbach acoefficients for various scales of its English version range 0.79 to 0.95 (20). The scales have been translated into Persian using a forward-backward method by Ardabily et al. Repeatability of the Persian version has also been confirmed using test-retest method (21).

We obtained written permission from the Persian translators. As we thought that some cultural differences may affect on the validity of the scale, we asked 10 experts to give their comments on the content validity of the scales and minor modifications were done on the scale. The scale was administered twice to 20 eligible women within a 7 days interval (test-retest). In our sample, ICC was 0.895 (0.754-0.957) and Cronbach alphas were 0.870.93 for the CTS2 subscales.

The English version of CTS2 has high internal consistency with Cronbach a 0.79 to 0.95 for its various scales (20). The instrument was translated into Persian using forward-backward procedure (21). Reliability of the translated version has been confirmed using test-retest method in a pilot test with 20 participants. ICC (CI 95\%) was 0.895 (0.754-0.957) and Cronbach alphas (internal consistency) was $0.87-0.93$ for the CTS2 in all subscales.

Demographic characteristics were determined by some relevant items of DHS (demographic and health surveys) (22). Items included factors such as age, the type of disease, disease duration, education level, employment status, marriage age, the duration of marriage, divorce history, the number of children, and the adequacy of income. The CTS-2, WAST, WHOQOL-BREF, and demographic questionnaires were completed, respectively.

According to the prevalence of violence (66\%) in Iran (2), the sample size was calculated 400 by considering $P=50 \%$ ( $P$ for the highest sample size), $d=5 \%$ and $\alpha=0.05$.

The curve of receiver operating characteristic (ROC) was used to analyze the overall accuracy of WAST and WAST-SF compared to the standard tool (CTS-2) and diagnostic capability of the tools was measured using the area under the curve (AUC). In the consecutive cut-off points, sensitivity and specificity with $95 \% \mathrm{CI}$, positive and negative predictive values (PPV and NPV), and positive and negative likelihood ratio (LR) were determined. Kappa correlation coefficient was used to determine the correlation of the results of overall 8-item WAST and WAST-SF with CTS-2 to identify the presence of violence. Data were analyzed by SPSS,16.0.

\section{Results}

Data were collected from 400 women between November 2014 and January 2016. The mean age of the women was $36(\mathrm{SD}=8)$ year. Slightly more than the half of women (56\%) and their husbands (52\%) had secondary education, $253(63.2 \%)$ of them were hospitalized, $45 \%$ had bipolar disorder (BMD), and disease duration of $43 \%$ of them was more than 5 years. In addition, 321 women (80\%) were housewives and $15 \%$ had a history of divorce and $23 \%$ of them reported sufficient household income (Table 1).

The optimal cut-off point for overall 8-item WAST score was 12 with 0.90 (95\% CI: 0.83 to 0.98 ) AUC (Figure 1), $96 \%$ (95\% CI, from $93 \%$ to $98 \%$ ) sensitivity, $84 \%$ (95\% CI, from $67 \%$ to $93 \%$ ) specificity, 99\% PPV, 63\% NPV, 5.94 positive LR, and 0.04 negative LR. At cut-off points of both 13 (cut-off point proposed by the tool developers) and 11 , AUC fell to 0.85 . Sensitivity and specificity at the cut-off point of 13 were $80 \%$ and $90 \%$ and at the cut-off point of 11 were $97 \%$ and $74 \%$. (Table 2).

The optimal cut-off point for WAST-SF was 3 (identical with the dichotomous scoring of WAST-SF) with 0.84 (95\% CI, from 0.77 to 0.91 ) AUC, $93 \%$ (95\% CI, from 90\% to $95 \%$ ) sensitivity, and $71 \%$ ( $95 \% \mathrm{CI}$, from $53 \%$ to $83 \%$ ) specificity. At the cut-off point of 4 , although specificity increased to $87 \%$, sensitivity fell to $76 \%$ (Table 2 ).

The optimal cut-off for the 6-item WAST (items 3-8)

Table 1. Demographic Characteristics of 19-49 Years Women With Mental Disorders $(\mathrm{N}=400)$

\begin{tabular}{|c|c|}
\hline \multicolumn{2}{|l|}{ Socio-demographics Characteristics } \\
\hline \multicolumn{2}{|l|}{ Woman age group (y), No. $(\%)^{*}$} \\
\hline $19-24$ & $40(10.0)$ \\
\hline $25-34$ & $152(38.0)$ \\
\hline$\geq 35$ & $208(52.0)$ \\
\hline $\operatorname{Mean}(S D)^{* *}$ & $36( \pm 8)$ \\
\hline \multicolumn{2}{|l|}{ Educational level of wife (y), No. (\%)* } \\
\hline Guidance (5) & $102(25.5)$ \\
\hline High school (6-12) & $218(54.5)$ \\
\hline University (> 13) & $80(20.0)$ \\
\hline \multicolumn{2}{|c|}{ Educational level of husband (y), No. (\%)* } \\
\hline Illiterate & $41(10.2)$ \\
\hline Primary (1-5) & $75(18.8)$ \\
\hline High school (6-12) & $207(51.8)$ \\
\hline University & $77(19.2)$ \\
\hline \multicolumn{2}{|l|}{ Wife age at first marriage (y), No. $(\%)^{*}$} \\
\hline$<20$ & $225(56.2)$ \\
\hline $21-30$ & $157(39.2)$ \\
\hline$>31$ & $18(4.5)$ \\
\hline \multicolumn{2}{|l|}{ Woman employment status, No. (\%) ${ }^{*}$} \\
\hline Employed & $79(19.8)$ \\
\hline Housewife & $321(80.2)$ \\
\hline \multicolumn{2}{|l|}{ Income, No. (\%) ${ }^{*}$} \\
\hline Sufficient & $92(23.0)$ \\
\hline Little sufficient & $197(49.2)$ \\
\hline Insufficient & $111(27.8)$ \\
\hline Divorce in the past, yes, No. $(\%)^{*}$ & $(15.0) 60$ \\
\hline \multicolumn{2}{|l|}{ Diagnosis } \\
\hline Schizophrenia and related disorders & $34(8.5)$ \\
\hline Bipolar affective disorder & $184(45.2)$ \\
\hline Depressive disorder & $88(22.0)$ \\
\hline Personality disorder & $29(7.8)$ \\
\hline Other & $65(16.2)$ \\
\hline Illness duration, mean (SD) & $1.7(1.1)$ \\
\hline \multicolumn{2}{|l|}{ Marital duration (y), No. (\%) ${ }^{*}$} \\
\hline$<5$ & $87(21.8)$ \\
\hline $6-10$ & $81(20.2)$ \\
\hline
\end{tabular}


Table 2. Operating Characteristics of the WAST and WAST-SF in Detecting Past-Year IPV at Different Cutoff Scores (N=400)

\begin{tabular}{lccccccc}
\hline $\begin{array}{l}\text { Cutoff } \\
\text { points }\end{array}$ & $\begin{array}{c}\text { Women With a Score at the Cutoff } \\
\text { or Higher }\end{array}$ & Sensitivity & Specificity & +LR & -LR & +PPV & -PPV \\
\hline \multicolumn{7}{r}{ Overall 8-item WAST (8-24) } \\
\hline 9 & $382(95.5)$ & $98.6(96.9-99.4)$ & $41.9(26.4-59.2)$ & 1.69 & 0.03 & $95.3(92.7-97.0)$ & $72.2(49.1-87.5)$ \\
10 & $377(94.2)$ & $98.4(96.5-99.3)$ & $54.8(54.8-37.8)$ & 2.17 & 0.03 & $96.3(93.9-97.8)$ & $73.9(53.5-87.5)$ \\
11 & $364(91.0)$ & $96.5(94.1-97.9)$ & $74.1(56.8-86.3)$ & 3.73 & 0.04 & $97.8(95.7-98.9)$ & $63.9(47.6-77.5)$ \\
12 & $359(89.8)$ & $95.6(93.4-97.5)$ & $83.9(67.4-92.9)$ & 5.94 & 0.04 & $98.6(96.8-99.4)$ & $63.4(48.1-76.4)$ \\
13 & $297(74.2)$ & $79.7(75.3-83.5)$ & $90.3(75.1-96.7)$ & 8.23 & 0.22 & $99.0(97.1-99.7)$ & $27.2(19.5-36.5)$ \\
14 & $239(59.8)$ & $64.5(59.5-69.2)$ & $96.8(83.8-99.4)$ & 19.00 & 0.36 & $96.8(97.7-99.9)$ & $18.6(13.4-25.4)$ \\
\hline & & WAST-SF (2-6) & & & & \\
\hline 3 & $353(88.2)$ & $93.2(90.2-95.4)$ & $71.0(53.4-83.9)$ & 3.21 & 0.09 & $97.5(95.2-98.7)$ & $46.8(33.3-60.8)$ \\
4 & $284(71.0)$ & $75.9(71.3-80.0)$ & $87.1(71.1-94.9)$ & 5.88 & 0.27 & $98.6(96.4-99.5)$ & $23.3(16.5-31.7)$ \\
5 & $138(34.5)$ & $37.1(32.4-42.2)$ & $96.8(83.8-99.4)$ & 11.59 & 0.65 & $99.3(96.0-99.9)$ & $11.5(8.1-15.9)$ \\
\hline & & WAST3-8 (6-18) & & & & \\
\hline 8 & $366(91.5)$ & $96.2(93.7-97.7)$ & $64.5(46.9-78.9)$ & 2.71 & 0.05 & $97.0(94.7-98.3)$ & $58.8(42.2-73.6)$ \\
9 & $326(81.5)$ & $87.3(83.5-90.3)$ & $87.1(71.1-94.9)$ & 6.76 & 0.14 & $98.8(96.9-99.5)$ & $36.5(26.4-47.9)$ \\
10 & $270(67.5)$ & $72.9(68.1-77.2)$ & $96.8(83.8-99.4)$ & 22.59 & 0.28 & $99.6(97.9-99.9)$ & $23.1(16.7-31.0)$ \\
\hline
\end{tabular}

Data are shown as Number (percent).

was 9 with 0.88 (95\% CI, from 0.82 to 0.94 ) AUC, $87 \%$ ( $95 \%$ CI, from $83 \%$ to $90 \%$ ) sensitivity and $87 \%$ (95\% CI, from $71 \%$ to $95 \%$ ) specificity. At the cut-off point of 10 , specificity increased to $97 \%$, but the sensitivity fell to $73 \%$ (Table 2).

The correlation of overall 8-item WAST score with CTS-2 was good $(r=0.69)$. The correlation of both WASTSF and WAST3- 8 with CTS- 2 was moderate $(r=0.58$ and $\mathrm{r}=0.52$, respectively). WAST-SF had a good correlation with overall 8 -item WAST score $(\mathrm{r}=0.67)$ and strong correlation with WAST 3-8 $(r=0.81)$.

The Prevalence of Violence

According to CTS-2, 349 women (87\%) experienced less severe violence, 292 women (74\%) experienced more severe violence, and in total 359 women (90\%) experienced less or more severe violence. Based on overall

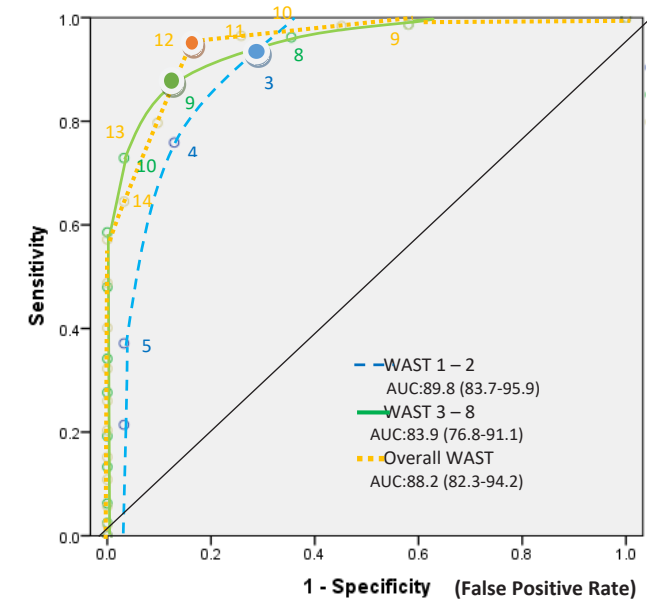

Figure 1. Receiver Operating Characteristic Curve of the WAST (N $=400$ ) for Detecting any IPV as Measured by the CTS-2 for any IPV.
8 -item WAST, with a cut-off point of 12,359 women (90\%) and based on WAST-SF, with a cut-off point of 3, 353 women $(88 \%)$ had experienced domestic violence. Detailed responses for each of the 8 items in the WAST are shown in Table 3.

Out of 359 women who identified as positive domestic violence victim based on the overall WAST, 354 women (98.6\%) had experienced domestic violence based on CTS-2 and out of 41 women who identified as negative domestic violence victim based on the WAST, 26 women (63.4\%) did not report domestic violence based on CTS-2 (Figure 2).

\section{Discussion}

The present study was conducted for the first time to assess the usefulness of WAST, a brief tool, for violence screening in women with psychiatric diseases compared to the comprehensive and commonly used reference standard, i.e. CTS-2. It also showed that WAST is a valid and reliable tool and a good diagnostic evaluation indicator to screen violence in psychiatric settings. The correlation between overall 8-item WAST and WAST-SF with the standard reference was good and moderate, respectively.

In such a population, the cut-off point of 12 had a good sensitivity and reasonable specificity in terms of screening women with psychiatric disease who had experienced domestic violence. This cut-off point compared to the cut-off point proposed by the tool developers (i.e. 13) was lower. The difference could be due to different reference standards being used and having very broad areas (at least 1 positive item on the minor or severe physical, sexual, or psychological aggression subscales) for the definition of IPV in this study. The difference could also be due to differences among study participants. In the original study, violence was assessed in women from general 
Table 3. Responses of WAST Items

\begin{tabular}{|c|c|}
\hline & Total $(\mathrm{N}=400)$ \\
\hline \multicolumn{2}{|c|}{$\begin{array}{l}\text { W1. In general, how would you describe your } \\
\text { relationship? }\end{array}$} \\
\hline A lot of tension & $116(29 \%)$ \\
\hline Some tension & $223(55.8 \%)$ \\
\hline No tension & $61(15.2 \%)$ \\
\hline \multicolumn{2}{|c|}{$\begin{array}{l}\text { W2. Do you and your partner work out arguments } \\
\text { with }\end{array}$} \\
\hline Great difficulty & $116(29 \%)$ \\
\hline Some difficulty & $168(42 \%)$ \\
\hline No difficulty & $116(29 \%)$ \\
\hline \multicolumn{2}{|c|}{$\begin{array}{l}\text { W3. Do arguments ever result in result in you feeling } \\
\text { put down or bad about yourself? }\end{array}$} \\
\hline Often & $161(40.2 \%)$ \\
\hline Sometimes & $153(38.2 \%)$ \\
\hline Never & $86(21.5 \%)$ \\
\hline \multicolumn{2}{|c|}{$\begin{array}{l}\text { W4. Do arguments ever result in hitting, kicking or } \\
\text { pushing? }\end{array}$} \\
\hline Often & $77(19.2 \%)$ \\
\hline Sometimes & $150(37.5 \%)$ \\
\hline Never & $173(43.2 \%)$ \\
\hline \multicolumn{2}{|c|}{$\begin{array}{l}\text { W5. Do you feel frightened by what your partner } \\
\text { says or does? }\end{array}$} \\
\hline Often & $107(26.8 \%)$ \\
\hline Sometimes & $157(39.2 \%)$ \\
\hline Never & $136(34 \%)$ \\
\hline \multicolumn{2}{|c|}{ W6. Has your partner ever abused you physically? } \\
\hline Often & $81(20.2 \%)$ \\
\hline Sometimes & $138(34.5 \%)$ \\
\hline Never & $181(45.2 \%)$ \\
\hline \multicolumn{2}{|c|}{ W7. Has your partner ever abused you emotionally? } \\
\hline Often & $170(42.5 \%)$ \\
\hline Sometimes & $163(40.8 \%)$ \\
\hline Never & $67(16.8 \%)$ \\
\hline \multicolumn{2}{|c|}{ W8. Has your partner ever abused you sexually? } \\
\hline Often & $41(10.2 \%)$ \\
\hline Sometimes & $82(20.5 \%)$ \\
\hline Never & $277(69.2 \%)$ \\
\hline
\end{tabular}

population attending primary health care clinics (18). Lower cut-off point for WAST has been also suggested in other studies; e.g. in a study on women attending primary care centers in Jakarta, Indonesia comparing WAST with the psychologist's determination, a cutoff score of 10 had the highest accuracy (15).

WAST-SF at the cut-off point of 3 identified $93 \%$ of women who experienced violence and $88 \%$ of women who did not experience it. It also had a moderate correlation with standard CTS-2 and a good correlation with the overall WAST. Therefore, it seems that it could be used for initially screening in busy centers and in positive cases, the next 6 items of WAST can be used to determine the type of violence. Vogel also suggested the use of the WAST-SF as a useful tool for violence screening in crowded centers in Afghanistan and Pakistan based on the results of their review study on violence screening tools (23). However, since the 2questions in the tool are not screening any of IPV areas, the WAST-SF on its own should not be used to screen IPV as suggested in the recent review by Arkins et al (13).

The prevalence of $90 \%$ of experience of domestic violence in the subjects was at the upper limit of the range, i.e. $15 \%$ to $92 \%$. It was also reported for the prevalence of violence among female outpatients or inpatients with psychiatric disorders in a review (24). High IPV prevalence in this study may be explained by some societal reasons such as acceptability of domestic violence as a means to resolve couples conflict and low levels of legal literacy. Furthermore, it may be due to research methodologies used. CTS-2 yield the highest rates of IPV compared with most of other commonly used scales (25). In most studies, only physical (26) or sexual assault (27) have been considered as violence but in our study even any minor psychological aggression has been considered as violence.

To our knowledge, this is the first study to assess

\begin{tabular}{|c|c|c|c|c|}
\hline \multirow{4}{*}{$\begin{array}{l}\text { Victimization } \\
\text { CTS2* }\end{array}$} & & CTS2 & \multirow{4}{*}{$\begin{array}{l}\text { Sensitivity } \\
\%(95 \% \mathrm{CI})\end{array}$} & \multirow{4}{*}{$\begin{array}{l}\text { Specificity } \\
\%(95 \% \text { CI })\end{array}$} \\
\hline & & \multirow[t]{3}{*}{+} & & \\
\hline & $\approx+$ & & & \\
\hline & $3-$ & & & \\
\hline \multirow{2}{*}{ Less Severe } & 349 & 10 & \multirow{2}{*}{96.4 (98.0-97.9) } & \multirow{2}{*}{$73.7(58.0-85.0)$} \\
\hline & 13 & 28 & & \\
\hline \multirow{2}{*}{ More Severe } & 311 & 48 & \multirow{2}{*}{98.4 (96.4-99.3) } & \multirow{2}{*}{$42.9(32.8-53.5)$} \\
\hline & 5 & 36 & & \\
\hline \multirow{2}{*}{ Both } & 354 & 5 & \multirow{2}{*}{$95.9(93.4-97.5)$} & \multirow{2}{*}{$83.0(67.4-92.9)$} \\
\hline & 15 & 26 & & \\
\hline
\end{tabular}

Figure 2. Sensitivity and specificity of the Woman Abuse Screening Tool (WAST) with cutoff point 12 as compared with the revised conflict tactics scale (CTS2).

${ }^{*}$ At least once in one of the psychological, physical, or sexual type during the past 12 months. 
the psychometric properties of the WAST in Iranian population and this is for the first time in the world that the gold standard CTS-2 was used to determine the accuracy of this tool in women with mental disorders. The focus on women with mental disorders creates a basis to identify an appropriate violence screening tool and plans effective interventions to support them as vulnerable women. After taking written informed consent, all participants answered all questions with not missing value, probably due to face to face interview which can be considered as a strength of the study.

The present study was conducted at an educational psychiatric hospital in the north west of Iran which covers about $10 \%$ of the population in Iran including different ethnic groups such as Azeri, Kurd, and Persian. However, similar studies in different geographical areas are needed to generalize the results.

According to the World Health Organization (WHO), identifying the type of abuse helps mental health professionals to develop a specific safety plan for patients with a mental disorder (4). IPV victims do not want to voluntarily disclose experience of IPV with their health care providers and their providers may ignore the signs and symptoms of domestic violence in the absence of screening. To be able to adequately care of and provide professional support for these women, psychiatric services need to improve the detection of violence by using an accurate screening tool.

According to the results, WAST can be used as screening tools in psychiatric settings due to the good correlation with CTS-2 (gold standard) at cutoff point of 12 to assess all 3 areas of IPV (physical, sexual, and psychological). Moreover, WAST-SF could also be used for initially screening of IPV in busy settings. However, further studies are needed in this regard to generalize the results to other settings.

\section{Conflict of Interests}

Authors declare that they have no conflict of interests.

\section{Ethical Issues}

This study was approved by ethical committee of Tabriz University of Medical Sciences (code number 6544/4/5, dated October 9, 2014).

\section{Financial Support}

This study is a part of a thesis approved and sponsored by Tabriz University of Medical Sciences.

\section{Acknowledgements}

Hereby, we greatly appreciate the cooperation provided by the Treatment Deputy, all personnel in teaching hospital of Razi-Tabriz, people who helped us in data collection procedures, and finally all participants.

\section{References}

1. WHO. Responding to intimate partner violence and sexual violence against women: WHO clinical and policy guidelines. Geneva: World Health Organization; 2013.

2. Ghazi Tabatabai M, Mohsen Tabrizi A, Marjai S. Studies on domestic violence against women. Tehran: Office of Public Affairs, Ministry of Interior Center of Women and Family Affairs, Presidency Islamic Republic Iran; 2004.

3. Ellsberg M, Jansen HA, Heise L, Watts $\mathrm{CH}$, GarciaMoreno C. Intimate partner violence and women's physical and mental health in the WHO multi-country study on women's health and domestic violence: an observational study. Lancet. 2008;371(9619):1165-1172. doi:10.1016/ s0140-6736(08)60522-x

4. Dillon G, Hussain R, Loxton D, Rahman S. Mental and Physical Health and Intimate Partner Violence against Women: A Review of the Literature. Int J Family Med. 2013;2013:313909. doi:10.1155/2013/313909

5. Khalifeh H, Oram S, Trevillion K, Johnson S, Howard LM. Recent intimate partner violence among people with chronic mental illness: findings from a national crosssectional survey. Br J Psychiatry. 2015;207(3):207-212. doi:10.1192/bjp.bp.114.144899

6. Trevillion K, Oram S, Feder G, Howard LM. Experiences of domestic violence and mental disorders: a systematic review and meta-analysis. PLoS One. 2012;7(12):e51740. doi:10.1371/journal.pone.0051740

7. Edmond T, Bowland S, Yu M. Use of Mental Health Services by Survivors of Intimate Partner Violence. Soc Work Ment Health. 2013;11(1):34-54. doi:10.1080/15332985.2012.7341 80

8. Campbell JC. Health consequences of intimate partner violence. Lancet. 2002;359(9314):1331-1336. doi:10.1016/ s0140-6736(02)08336-8

9. Devries K, Watts C, Yoshihama M, et al. Violence against women is strongly associated with suicide attempts: evidence from the WHO multi-country study on women's health and domestic violence against women. Soc Sci Med. 2011;73(1):79-86. doi:10.1016/j.socscimed.2011.05.006

10. Wathen CN, Jamieson E, MacMillan HL. Who is identified by screening for intimate partner violence? Womens Health Issues. 2008;18(6):423-432. doi:10.1016/j.whi.2008.08.003

11. Yildizhan R, Adali E, Kolusari A, Kurdoglu M, Yildizhan B, Sahin G. Domestic violence against infertile women in a Turkish setting. Int J Gynaecol Obstet. 2009;104(2):110112. doi:10.1016/j.ijgo.2008.10.007

12. García-Moreno C. Global and regional estimates of violence against women: prevalence and health effects of intimate partner violence and non-partner sexual violence. World Health Organization; 2013.

13. Arkins B, Begley C, Higgins A. Measures for screening for intimate partner violence: a systematic review. J Psychiatr Ment Health Nurs. 2016;23(3-4):217-235. doi:10.1111/ jpm.12289

14. Krug EG, Mercy JA, Dahlberg LL, Zwi AB. El informe mundial sobre la violencia y la salud. Biomedica. 2002;22:327-336. doi:10.7705/biomedica.v22iSupp2.1182

15. Nelson HD, Bougatsos C, Blazina I. Screening women for intimate partner violence: a systematic review to update the U.S. Preventive Services Task Force recommendation. Ann Intern Med. 2012;156(11):796-808, w-279, w-280, w-281, w-282. doi:10.7326/0003-4819-156-11-201206050-00447

16. Rabin RF, Jennings JM, Campbell JC, Bair-Merritt MH. Intimate partner violence screening tools: a systematic review. Am J Prev Med. 2009;36(5):439-445.e434. 
doi:10.1016/j.amepre.2009.01.024

17. MacMillan HL, Wathen CN, Jamieson E, et al. Approaches to screening for intimate partner violence in health care settings: a randomized trial. Jama. 2006;296(5):530-536. doi:10.1001/jama.296.5.530

18. Brown JB, Lent B, Brett PJ, Sas G, Pederson LL. Development of the Woman Abuse Screening Tool for use in family practice. Fam Med. 1996;28(6):422-428.

19. Brown JB, Lent B, Schmidt G, Sas G. Application of the Woman Abuse Screening Tool (WAST) and WAST-short in the family practice setting. J Fam Pract. 2000;49(10):896903.

20. Straus MA, Hamby SL, Boney-McCoy S, Sugarman DB. The Revised Conflict Tactics Scales (CTS2):Development and Preliminary Psychometric Data. J Fam Issues. 1996;17(3):283-316. doi:10.1177/019251396017003001

21. Ardabily HE, Moghadam ZB, Salsali M, Ramezanzadeh F, Nedjat S. Prevalence and risk factors for domestic violence against infertile women in an Iranian setting. Int J Gynaecol Obstet. 2011;112(1):15-17. doi:10.1016/j.ijgo.2010.07.030

22. Hindin MJ, Kishor S, Ansara DL. Intimate Partner Violence among Couples in 10 DHS Countries: Predictors and Health Outcomes. https://dhsprogram.com/pubs/pdf/
AS18/AS18.pdf. Published 2008.

23. Vogel J. Effective gender-based violence screening tools for use in primary health care settings in Afghanistan and Pakistan: a systematic review. East Mediterr Health J. 2013;19(3):219-226.

24. Howard LM, Trevillion K, Khalifeh H, Woodall A, AgnewDavies R, Feder G. Domestic violence and severe psychiatric disorders: prevalence and interventions. Psychol Med. 2010;40(6):881-893. doi:10.1017/s0033291709991589

25. Desmarais SL, Reeves KA, Nicholls TL, Telford RP, Fiebert MS. Prevalence of physical violence in intimate relationships, Part 1: Rates of male and female victimization. Partner Abuse. 2012;3(2):140-169. doi:10.1891/1946-6560.3.2.140

26. Reichenheim ME, Moraes CL. Comparison between the abuse assessment screen and the revised conflict tactics scales for measuring physical violence during pregnancy. J Epidemiol Community Health. 2004;58(6):523-527. doi:10.1136/jech.2003.011742

27. Bennice JA, Resick PA, Mechanic M, Astin M. The relative effects of intimate partner physical and sexual violence on post-traumatic stress disorder symptomatology. Violence Vict. 2003;18(1):87-94. doi:10.1891/vivi.2003.18.1.87

(c) 2018 The Author (s); This is an open-access article distributed under the terms of the Creative Commons Attribution License (http://creativecommons.org/licenses/by/4.0), which permits unrestricted use, distribution, and reproduction in any medium, provided the original work is properly cited. 